Citation: D. Aiello, G. Gusella, A. Fiorenza, V. Guarnaccia, G. Polizzi (2020) Identification of Neofusicoccum parvum causing Canker and Twig Blight on Ficus carica in Italy. Phytopathologia Mediterranea 59(1): 213-218. doi: 10.14601/Phyto-10798

Accepted: November 22, 2019

Published: April 30, 2020

Copyright: (c) 2020 D. Aiello, G. Gusella, A. Fiorenza, V. Guarnaccia, G. Polizzi. This is an open access, peerreviewed article published by Firenze University Press (http://www.fupress. $\mathrm{com} / \mathrm{pm}$ ) and distributed under the terms of the Creative Commons Attribution License, which permits unrestricted use, distribution, and reproduction in any medium, provided the original author and source are credited.

Data Availability Statement: All relevant data are within the paper and its Supporting Information files.

Competing Interests: The Author(s) declare(s) no conflict of interest.

Editor: Alan J.L. Phillips.
New or Unusual Disease Reports

\section{Identification of Neofusicoccum parvum causing canker and twig blight on Ficus carica in Italy}

\author{
Dalia AiEllo ${ }^{1, *}$, Giorgio GUSELlA ${ }^{1}$, Alberto FiORENZA ${ }^{1}$, Vladimiro \\ GUARNACCIA $^{2,3}$, GIANCARLO POLIZZI ${ }^{1}$ \\ ${ }^{1}$ Dipartimento di Agricoltura, Alimentazione e Ambiente, sezione Patologia Vegetale, \\ University of Catania, Via S. Sofia 100, 95123 Catania, Italy \\ ${ }^{2}$ DiSAFA, University of Torino, Largo Paolo Braccini, 2, 10095 Grugliasco, TO, Italy \\ ${ }^{3}$ Centre for Innovation in the Agro-Environmental Sector, AGROINNOVA, University of \\ Torino, Largo Braccini 2, 10095 Grugliasco (TO), Italy \\ ${ }^{\star}$ Corresponding author: dalia.aiello@unict.it
}

Summary. During June 2018, several symptomatic fig (Ficus carica) cuttings, showing twig blight, subcortical discolouration and apical dieback were collected from a nursery in Catania province, Sicily (Italy). Isolations from diseased tissue consistently showed the presence of the same fungal colony. Morphology of the fungal isolates together with sequence data of the nuclear rDNA internal transcriber spacer (ITS) region, translation elongation factor 1-alpha (tef1) gene and partial beta-tubulin ( $t u b 2)$ gene of representatives isolates revealed the presence of the fungus Neofusicoccum parvum. Pathogenicity tests were conducted by inoculating fig cuttings with mycelial plugs. After 10 days, the inoculated plants developed cankers similar to those observed in the greenhouse and after 26 days all inoculated plants were dead. To the best of our knowledge, this is the first report worldwide of N. parvum causing disease on this host.

Keywords. Fig cuttings, pathogenicity, molecular analysis, Botryosphaeriaceae.

\section{INTRODUCTION}

Fig (Ficus carica L.) is one of the most cultivated crop of the Mediterranean basin Countries. Several diseased caused by bacteria, viruses, oomycetes and fungi are reported for this crop throughout the world (Ferguson et al., 1990).

In the last years, there has been increased interest in "edible landscapes" and some woody ornamental plant genera or species are selected for attractive garden plants that also have edible fruit. Small edible ornamental figs obtained from cutting are produced in Sicily both for aesthetic value as well as consumption. During June 2018, examination of 1,500 fig cuttings in an ornamental nursery in Catania province, Sicily (Italy), revealed that up to $20 \%$ of the plants showed canker and twig blight during the rooting step of the propagation process. Therefore, the aim of this study was to identify the causal agent of canker and twig blight on fig in Sicily, Italy. 


\section{MATERIAL AND METHODS}

Isolation and morphological characterization of the pathogen

Twenty symptomatic fig cuttings, showing canker and twig blight were collected from a greenhouse in Catania province, Sicily (Italy) during the rooting step of the propagation process. Small sections of diseased woody tissue were surface disinfected for $1 \mathrm{~min}$ in $1.5 \%$ sodium hypochlorite, rinsed in sterile water, placed on potato dextrose agar (3.9\% PDA, Oxoid) amended with $100 \mathrm{mg} /$ liter of streptomycin sulfate (Sigma-Aldrich) to prevent bacterial growth, and then incubated at $25 \pm$ $1^{\circ} \mathrm{C}$ for three-four days. A total of 12 morphologically similar isolates were obtained from single conidium or hyphal tip of pure cultures on PDA at $25 \pm 1^{\circ} \mathrm{C}$. For the morphological characterization of the pathogen, the isolates were transferred on PDA and technical agar (TA, $1.2 \%$ agar, Oxoid) with sterilized pine needles deposited onto the surface, and then incubated in a growth chamber at $25 \pm 1^{\circ} \mathrm{C}$ with a $12 \mathrm{~h}$ photoperiod. Size and shape of conidia were recorded from colonies grown on TA with sterilized pine needles after 3 weeks.

\section{Pathogenicity tests}

Pathogenicity tests were conducted on eighteen potted, healthy, 1-month-old cuttings of fig, with the same number for the control. A piece of bark was removed with a $6 \mathrm{~mm}$ diam. cork borer and 6-mm-diameter mycelial plugs taken from a 7-day-old culture of isolate Di3AFC1 (CBS 145622) were applied to two separate wounds on each twig. The wounds were covered with Parafilm (Pechney Plastic Packaging Inc., Chicago, USA) to prevent desiccation. Controls consisted of sterile PDA plugs applied to wounds. All replicates were kept in a growth chamber with a $12 \mathrm{~h}$ photoperiod at $25 \pm$ $1^{\circ} \mathrm{C}$. The presence and length of the resulting lesions was recorded 10, 14 and 26 days after inoculation.

\section{Molecular identification}

Genomic DNA was extracted from isolates Di3AFC1, Di3AFC2 and Di3AFC3 (CBS 145622, CBS 145623 and CBS 145624) using the Wizard Genomic DNA Purification Kit (Promega Corporation, WI, USA). The internal transcriber spacer region (ITS) of the nuclear ribosomal RNA operon was amplified with primers ITS5 and ITS4 (White et al., 1990), the primers EF1-728F and EF1-986R (Carbone and Kohn, 1999) were used to amplify part of the translation elongation factor 1alpha gene (tef1) while the primer set $\mathrm{Bt}-2 \mathrm{a}$ and $\mathrm{Bt}-2 \mathrm{~b}$ (Glass and Donaldson 1995) were used for the partial beta-tubulin (tub2) gene. The PCR products were sequenced in both directions by Macrogen Inc. (South Korea). The DNA sequences generated were analysed and consensus sequences were computed using the program Geneious v. 11.1.5.

\section{Phylogenetic analysis}

The sequences obtained in this study were blasted against the NCBIs GenBank nucleotide database to determine the closest relatives to be included in the phylogenetic analysis. Blast analisys indicated that all the isolates belonged to the genus Neofusicoccum. Sequence alignments of the different gene regions, including sequences generated in this study and sequences downloaded from GenBank, were initially performed using the MAFFT v. 7 online server (http://mafft.cbrc.jp/alignment/server/index. html) (Katoh and Standley, 2013), and then manually adjusted in MEGA v. 7 (Kumar et al., 2016). To establish the identity of fungal isolates, phylogenetic analyses were conducted using individual locus (data not shown) as well as concatenated analyses of three loci (ITS, tef1 and tub2). Additional reference sequences were selected based on recent studies on Neofusicoccum genus (Yang et al., 2017). Phylogenetic analyses were based on Maximum Parsimony (MP) for all the individual loci and on both MP and Bayesian Inference (BI) for the combined multilocus analyses. For BI, the best evolutionary model for each partition was selected based on MrModeltest v. 2.3 (Nylander 2004) and incorporated into the analyses. MrBayes v. 3.2.5 (Ronquist et al., 2012) was used to generate phylogenetic trees under optimal criteria per partition. The Markov Chain Monte Carlo (MCMC) analysis used four chains and started from a random tree topology. The heating parameter was set to 0.2 and trees were sampled every 1000 generations. Analyses stopped once the average standard deviation of split frequencies was below 0.01. The MP analysis was done using PAUP (Swofford, 2003). Phylogenetic relationships were estimated by heuristic searches with 100 random addition sequences. Tree bisection- reconnection was used, with the branch swapping option set on 'best trees' only with all characters weighted equally and alignment gaps treated as fifth state. Tree length (TL), consistency index (CI), retention index (RI) and rescaled consistence index (RC) were calculated for parsimony and the bootstrap analyses (Hillis \& Bull 1993) were based on 1000 replicates. Sequences generated in this study were deposited in GenBank (Table 1). 
Table 1. Collection details and GenBank accession numbers of isolates included in this study.

\begin{tabular}{|c|c|c|c|c|c|c|}
\hline \multirow{2}{*}{ Species } & \multirow{2}{*}{ Culture no. ${ }^{1}$} & \multirow{2}{*}{ Host } & \multirow{2}{*}{ Country } & \multicolumn{3}{|c|}{ GenBank no. $^{2}$} \\
\hline & & & & ITS & tef1 & $t u b 2$ \\
\hline Diplodia seriata & CBS 110875 & Vitis vinifera & South Africa & AY343456 & KX464592 & KX464827 \\
\hline Neofusicoccum arbuti & CBS $116131^{\mathrm{T}}$ & Arbutus menziesii & USA: Washington & AY819720 & KF531792 & KF531793 \\
\hline \multirow[t]{2}{*}{ N. australe } & CBS $139662^{\mathrm{T}}$ & Acacia sp. & Australia & AY339262 & AY339270 & AY339254 \\
\hline & CBS 121115 & Prunus persica & South Africa & EF445355 & EF445386 & KX464948 \\
\hline N. batangarum & CBS $124924^{\mathrm{T}}$ & Terminalia catappa & Cameroon & FJ900607 & FJ900653 & FJ900634 \\
\hline N. cryptoaustrale & CBS $122813^{\mathrm{T}}$ & Eucalyptus sp. & South Africa & FJ752742 & FJ752713 & FJ752756 \\
\hline N. kwambonambiense & CBS $102.17^{\mathrm{T}}$ & Carya illinoensis & USA: Florida & KX464169 & KX464686 & KX464964 \\
\hline N. luteum & CBS $562.92^{\mathrm{T}}$ & Actinidia deliciosa & New Zealand & KX464170 & KX464690 & KX464968 \\
\hline N. mangiferae & CBS 118532 & Mangifera indica & Australia & AY615186 & DQ093220 & AY615173 \\
\hline N. mediterraneum & CBS $121718^{\mathrm{T}}$ & Eucalyptus sp. & Greece & GU251176 & GU251308 & - \\
\hline \multirow[t]{5}{*}{ N. parvum } & CBS 123650 & Syzygium cordatum & South Africa & KX464182 & KX464708 & KX464994 \\
\hline & CMW $9081^{\mathrm{T}}$ & Populus nigra & New Zealand & AY236943 & AY236888 & AY236917 \\
\hline & Di3AFC1 & Ficus carica & Italy & MN611179 & MN623346 & MN623343 \\
\hline & Di3AFC2 & Ficus carica & Italy & MN611180 & MN623347 & MN623344 \\
\hline & Di3AFC3 & Ficus carica & Italy & MN611181 & MN623348 & MN623345 \\
\hline N. pistaciarum & CBS $113083^{\mathrm{T}}$ & Pistacia vera & USA: California & KX464186 & KX464712 & KX464998 \\
\hline N. protearum & CBS 114176 & Leucadendron laureolum & South Africa & AF452539 & KX464720 & KX465006 \\
\hline \multirow[t]{2}{*}{ N. stellenboschiana } & CBS $110864^{\mathrm{T}}$ & Vitis vinifera & South Africa & AY343407 & AY343348 & KX465047 \\
\hline & CBS 121116 & Prunus armeniaca & South Africa & EF445356 & EF445387 & KX465049 \\
\hline N. terminaliae & CBS 125264 & Terminalia sericea & South Africa & GQ471804 & GQ471782 & KX465053 \\
\hline N. vitifusiforme & CBS $110887^{\mathrm{T}}$ & Vitis vinifera & South Africa & AY343383 & AY343343 & KX465061 \\
\hline
\end{tabular}

${ }^{1}$ CBS: Westerdijk Fungal Biodiversity Institute, Utrecht; CMW: Tree Pathology Co-operative Program, Forestry and Agricultural Biotechnology Institute, University of Pretoria, South Africa; Di3A: Dipartimento di Agricoltura Alimentazione e Ambiente. Ex-type and ex-epitype cultures are indicated with ${ }^{\mathrm{T}}$.

${ }^{2}$ ITS: internal transcribed spacers 1 and 2 together with 5.8S nrDNA; tef1: translation elongation factor 1-alpha; tub2: partial beta-tubulin gene. Sequences generated in this study are indicated in italics.

\section{RESULTS AND DISCUSSION}

Symptomatic plants showed cankers, shoot blight and subcortical discolouration (Figure 1a, b). One type of colony was consistently obtained from these symptomatic tissues. A total of 12 fungal isolates were established from single conidium or hyphal tip cultures on PDA. The isolates developed abundant, aerial mycelium that became grey after 2-3 days and then black with age. On pine needles the isolates formed black, globose pycnidia after 3 weeks. Conidia were hyaline, non-septate, ellipsoid, thin walled and measured 14-20 × 4.5-7 $\mu \mathrm{m}$. After 10 days from inoculation cankers, characterized by discolouration and necrotic internal tissue, developed at both inoculation points with an average lesion length of $14.5 \mathrm{~cm}$. Pycnidia developed above and near each lesion. Infection also resulted in shoot blight and apical dieback of the inoculated plants. After 14 days, $44 \%$ of the inoculated plants were dead and after 26 days, all the inoculated plants had died (Figure 1c, $\mathrm{d}, \mathrm{e})$. These symptoms on the inoculated plants were identical to those observed in diseased fig cuttings in the greenhouse. All the control plants, inoculated only with agar plugs, did not develop any symptoms. Some of the diseased tested plants were used to re-isolate the fungus in order to fulfill the Koch's postulates. These results confirm that the isolated fungus was the causal agent of the disease.

The three MP trees derived from the single gene sequence alignments (ITS, tef1 and tub2) produced topologically similar trees. The combined phylogeny of Neofusicoccum species consisted of 21 sequences, including the outgroup sequences of Diplodia seriata (culture CBS 110875). A total of 1262 characters (ITS: 1-507, tef1: 514-821, tub2: 828-1262) were included in the phylogenetic analysis. The results showed 114 characters were parsimony-informative, 185 were variable and parsimony-uninformative and 951 characters were constant. A maximum of 1000 equally most parsimonious trees were saved (Tree length $=438, \mathrm{CI}=0.811$, $\mathrm{RI}=0.842$ and $\mathrm{RC}=0.682$ ). Bootstrap support values from the parsimony analysis are plotted on the Bayes- 

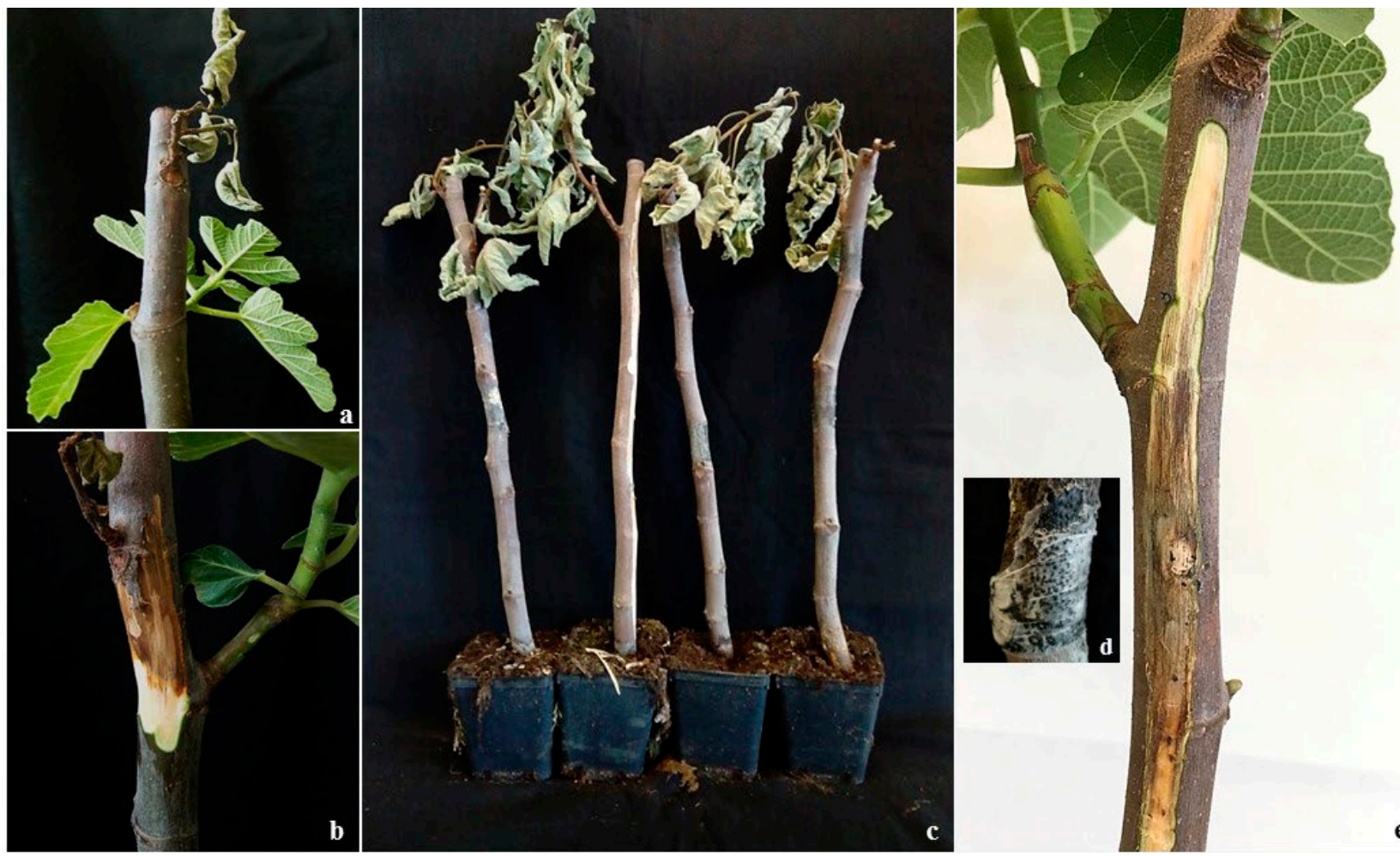

Figure 1. Natural symptoms of disease $(a, b)$ and disease symptoms reproduced from artificial inoculation of fig cuttings (c-e). a, shoot blight; $b$, internal discolouration; $c$, shoot blight and apical dieback 26 days after pathogen inoculation; d, dark pycnidia above the inoculation point; e, internal lesion and discolouration under the inoculation point after 10 days on artificially inoculated fig cuttings.

ian phylogenies in Figure 2. For the Bayesian analyses, MrModeltest suggested that all partitions should be analysed with dirichlet state frequency distributions. The following models were recommended by MrModeltest and used: $\mathrm{K} 80+\mathrm{I}+\mathrm{G}$ for ITS, HKY+G for tef1 and tub2. In the Bayesian analysis, the ITS partition had 74 unique site patterns, the tef1 partition had 118 unique site patterns and the $t u b 2$ partition had 62 unique site patterns, and the analysis ran for 1100000 generations, resulting in 2022 trees of which 1320 trees were used to calculate the posterior probabilities.

In the combined analyses, the three representative isolates clustered with one reference strain and the extype strain of N. parvum (CMW9081). The individual alignments and trees of the single loci used in the analyses were compared with respect to their performance in species recognition. According with morphological and molecular analyses, the isolates were identified as Neofusicoccum parvum (Pennycook \& Samuels) Crous, Slippers \& A.J.L. Phillips.

Fungi belonging to the Botryosphaeriaceae family are reported worldwide as pathogens of several Ficus species (Al-Bedak, 2018; Mohali et al., 2017; El-Atta and
Aref, 2013). The cultivated fig (F. carica), is reported to be attacked by different species in the Botryosphaeriaceae, including Lasiodiplodia theobromae (Pat.) Griffon \& Maubl. (Çeliker and Michailides, 2012) and Neoscytalidium dimidiatum (Penz.) Crous \& Slippers (Elshafie and Ba-Omar, 2002; Ray et al., 2010). Until now, N. parvum has been reported only on the ornamental Ficus microcarpa L. in association with other Botryosphaeriaceae species causing branch canker and dieback (Mayorquin et al., 2012).

Neofusicoccum parvum, characterized by the proven ability to induce disease, has a very wide geographical and host distribution (Sakalidis et al., 2013), and in Italy was already reported to cause several diseases on different woody hosts, like olive (Carlucci et al., 2013), mango (Ismail et al., 2013), avocado (Guarnaccia et al., 2016;), loquat (Giambra et al., 2016), pomegranate (Riccioni et al., 2017) grapevine (Mondello et al., 2013; Carlucci et al., 2015) and Rhaphiolepis indica (Gusella et al., 2020). Since N. parvum has been reported on the genus Ficus, although on a different species (Mayorquin et al., 2012), it is no surprise to find it on another species of the same genus. Nevertheless, we need to point out that in this 
case $N$. parvum was found causing serious disease on an important crop for the southern regions of in Italy, and for several other countries of the Mediterranean Basin, like Turkey, Morocco, Egypt and Algeria. In addition, we need to highlight that this report refers to the propagation process of fig cuttings that represents a crucial step to avoid severe infections before the commercialization of this species in Italy and abroad. The recovery of this fungus from fig cuttings confirms its high diffusion in Italy and the high risk for other susceptible crops. To the best of our knowledge, this is the first report worldwide of the fungus $N$. parvum attacking F. carica.

\section{ACKNOWLEDGEMENTS}

This research was supported by Research Project 2016-2018 "Monitoraggio, caratterizzazione e controllo sostenibile di microrganismi e artropodi di interesse agrario" WP2 - 5A722192134.

\section{LITERATURE CITED}

Al-Bedak O.A., Mohamed R.A., Seddek N.H., 2018. First detection of Neoscytalidium dimidiatum associated

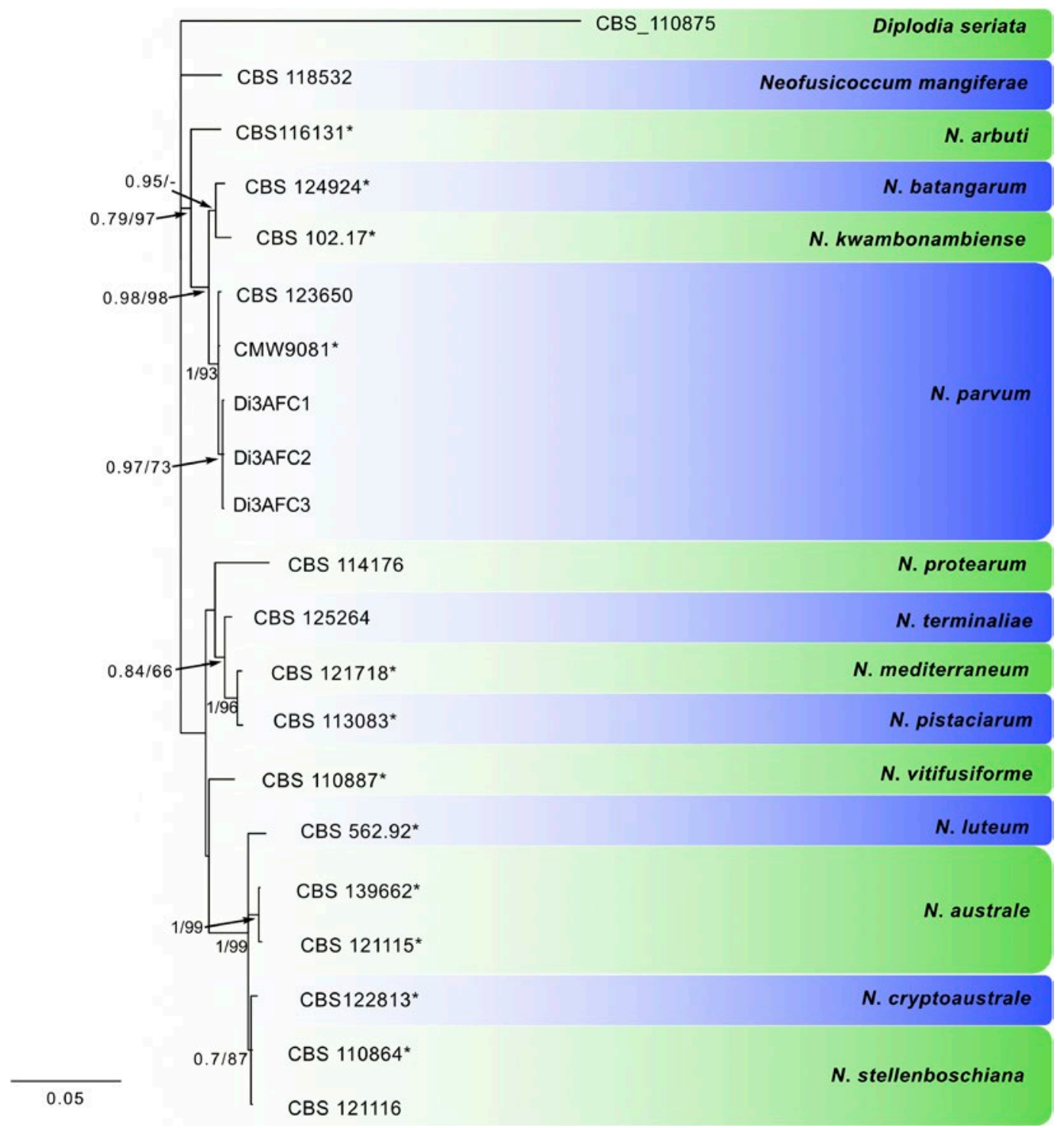

Figure 2. Consensus phylogram of 1320 trees resulting from a Bayesian analysis of the combined ITS, tef1 and tub2 sequences. Bootstrap support values and Bayesian posterior probability values are indicated at the nodes. Neofusicoccum species are listed next to the strain numbers. ${ }^{*}$ indicates ex-type strains. The tree was rooted to Diplodia seriata (CBS 110875). 
with canker disease in Egyptian Ficus trees. Forest Pathology 48: e12411.

Carbone I., Kohn L.M., 1999. A method for designing primer sets for speciation studies in filamentous ascomycetes. Mycologia 91: 553-556.

Carlucci A., Cibelli F., Lops F., Raimondo M.L., 2015. Characterization of Botryosphaeriaceae species as causal agents of trunk diseases on grapevines. Plant Disease 99: 1678-1688.

Carlucci A., Raimondo M.L., Cibelli F., Phillips A.J., Lops F., 2013. Pleurostomophora richardsiae, Neofusicoccum parvum and Phaeoacremonium aleophilum associated with a decline of olives in southern Italy. Phytopathologia Mediterranea 52: 517-527.

Çeliker N.M., Michailides T.J., 2012. First report of Lasiodiplodia theobromae causing canker and shoot blight of fig in Turkey. New Disease Reports 25: 12.

El-Atta H.A., Aref I.M., 2013. Pathogenic mortality of Ficus spp. International Journal of Plant, Animal and Environmental Sciences 3: 204-210.

Elshafie A.E., Ba-Omar T., 2002. First report of Albizia lebbeck dieback caused by Scytalidium dimidiatum in Oman. Mycopathologia 154: 37-40.

Ferguson L., Michailides T.J., Shorey H.H., 1990. The California fig industry. Horticultural Reviews 12: 409-490.

Giambra S., Piazza G., Alves A., Mondello V., Berbegal M., Burruano S., 2016. Botryosphaeriaceae species associated with diseased loquat trees in Italy and description of Diplodia rosacearum sp. nov. Mycosphere 7: 978-989.

Guarnaccia V., Vitale A., Cirvilleri G., Aiello D., Susca A., Polizzi G., 2016. Characterization and pathogenicity of fungal species associated with branch cankers and stem-end rot of avocado in Italy. European Journal of Plant Pathology 146: 963-976.

Gusella G., Aiello D., Polizzi G., 2020. First report of leaf and twig blight of Indian hawthorn (Rhaphiolepis indica) caused by Neofusicoccum parvum in Italy. Journal of Plant Pathology 102: 275.

Hillis D.M., Bull J.J., 1993. An empirical test of bootstrapping as a method for assessing confidence in phylogenetic analysis. Systematic Biology 42: 182-192.

Ismail A.M., Cirvilleri G., Lombard L., Crous P.W., Groenewald J.Z., Polizzi G., 2013. Characterization of Neofusicoccum species causing mango dieback in Italy. Journal of Plant Pathology 95: 549-557.

Katoh K., Standley D.M., 2013. MAFFT Multiple sequence alignment software version 7: improvements in performance and usability. Molecular Biology and Evolution 30: 772-780.

Kumar S., Stecher G., Tamura K., 2016. MEGA 7: molecular evolutionary genetics analysis version 7.0 for bigger datasets. Molecular Biology and Evolution 33: 1870-1874.

Mayorquin J.S., Eskalen A., Downer A.J., Hodel D.R., Liu A., 2012. First report of multiple species of the Botryosphaeriaceae causing bot canker disease of Indian laurel-leaf fig in California. Plant Disease 96: 459.

Mohali S.R., Castro-Medina F., Úrbez-Torres J.R., Gubler W.D., 2017. First report of Lasiodiplodia theobromae and $L$. venezuelensis associated with blue stain on Ficus insipida wood from the Natural Forest of Venezuela. Forest Pathology 47: e12355.

Mondello V., Lo Piccolo S., Conigliaro G., Alfonzo A., Torta L., Burruano S., 2013. First report of Neofusiccoccum vitifusiforme and presence of other Botryosphaeriaceae species associated with Botryosphaeria dieback of grapevine in Sicily (Italy). Phytopathologia Mediterranea 52: 388-396.

Nylander J.A.A., 2004. MrModeltest v. 2. Programme distributed by the author. Uppsala: Evolutionary Biology Centre, Uppsala University.

Ray J.D., Burgess T., Lanoiselet V.M., 2010. First record of Neoscytalidium dimidiatum and N. novaehollandiae on Mangifera indica and N. dimidiatum on Ficus carica in Australia. Australasian Plant Disease Notes 5: 48-50.

Riccioni L., Valente M.T., Giambattista G.D., 2017. First report of Neofusicoccum parvum causing shoot blight and plant decay on pomegranate in Tarquinia, Italy. Journal of Plant Pathology 99: 294.

Ronquist F., Teslenko M., van der Mark P., Ayres D.L., ... Huelsenbeck J.P., 2012. MrBayes 3.2: efficient Bayesian phylogenetic inference and model choice across a large model space. Systematic Biology 61, 539-542.

Sakalidis M.L., Slippers B., Wingfield B.D., Hardy G.S.J., Burgess T.I., 2013. The challenge of understanding the origin, pathways and extent of fungal invasions: global populations of the Neofusicoccum parvum-N. ribis species complex. Diversity and Distributions 19: 873-883.

Swofford D.L., 2003. PAUP*: phylogenetic analysis using parsimony ( ${ }^{*}$ and other methods), v. 4.0b10. Sunderland, MA: Sinauer Associates.

White T.J., Bruns T., Lee S. J.W.T., Taylor J.L., 1990. Amplification and direct sequencing of fungal ribosomal RNA genes for phylogenetics. In: PCR Protocols: a Guide to Methods and Applications (M.A. Innis, D.H. Gelfand, J.J. Sninsky, T.J. White, ed.), Academic Press, New York, USA, pp 315-321.

Yang T., Groenewald J.Z., Cheewangkoon, R., Jami, F., Abdollahzadeh, J., Lombard, L., Crous, P.W., 2017. Families, genera, and species of Botryosphaeriales. Fungal Biology 121, 322-346. 